\title{
A Novel Pyrene Excimer and Fluorogenic Probe for the Detection of Alkylating Agents
}

Yu Lin Jiang and Ann Marie Broome*

Department of Cell and Molecular Pharmacology \& Experimental Therapeutics, Medical University of South Carolina, Charleston, South Carolina 29425, United States

Proton and carbon NMR spectra of novel compounds $\mathbf{3}$ and $\mathbf{4}$ 


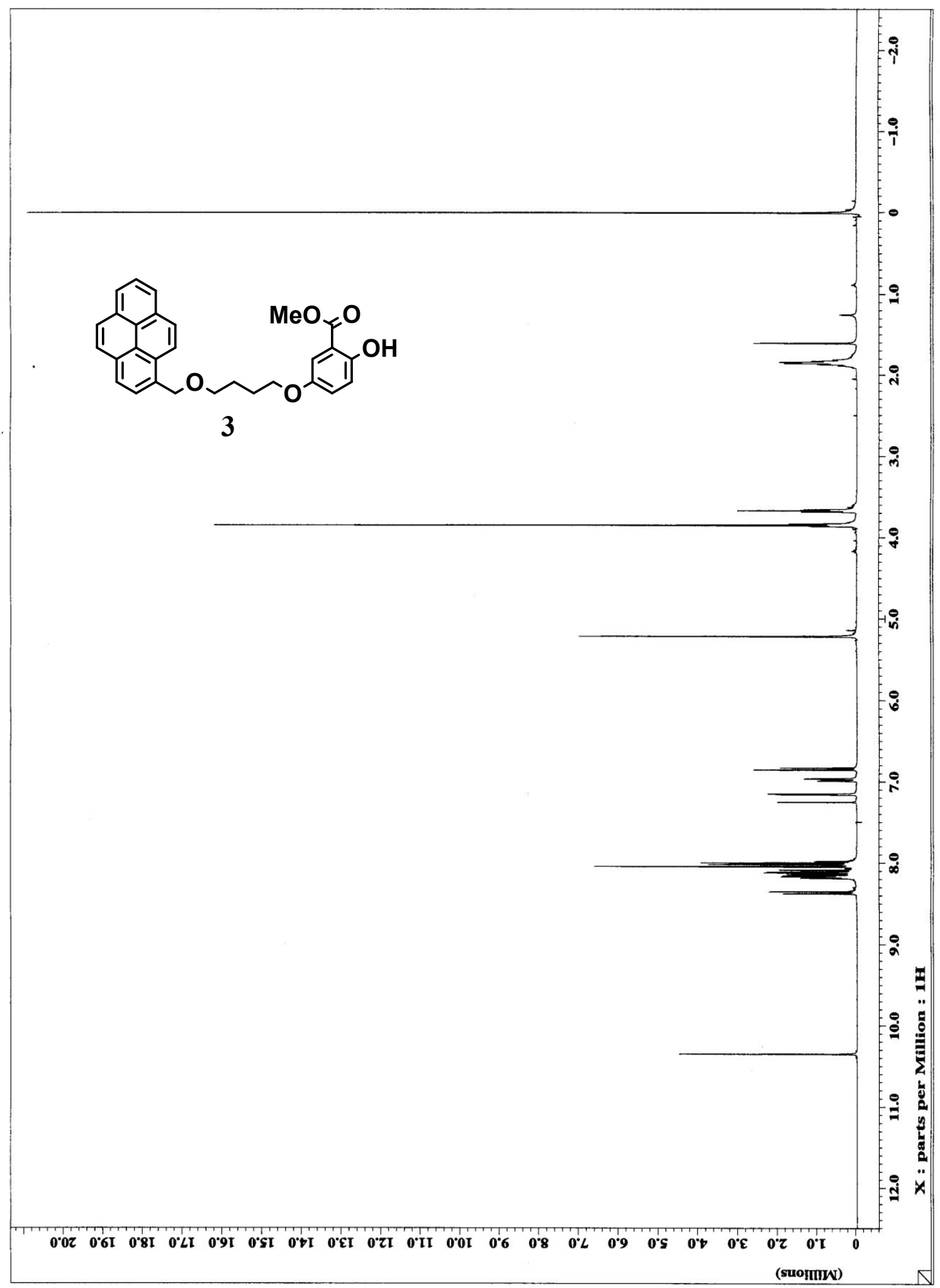




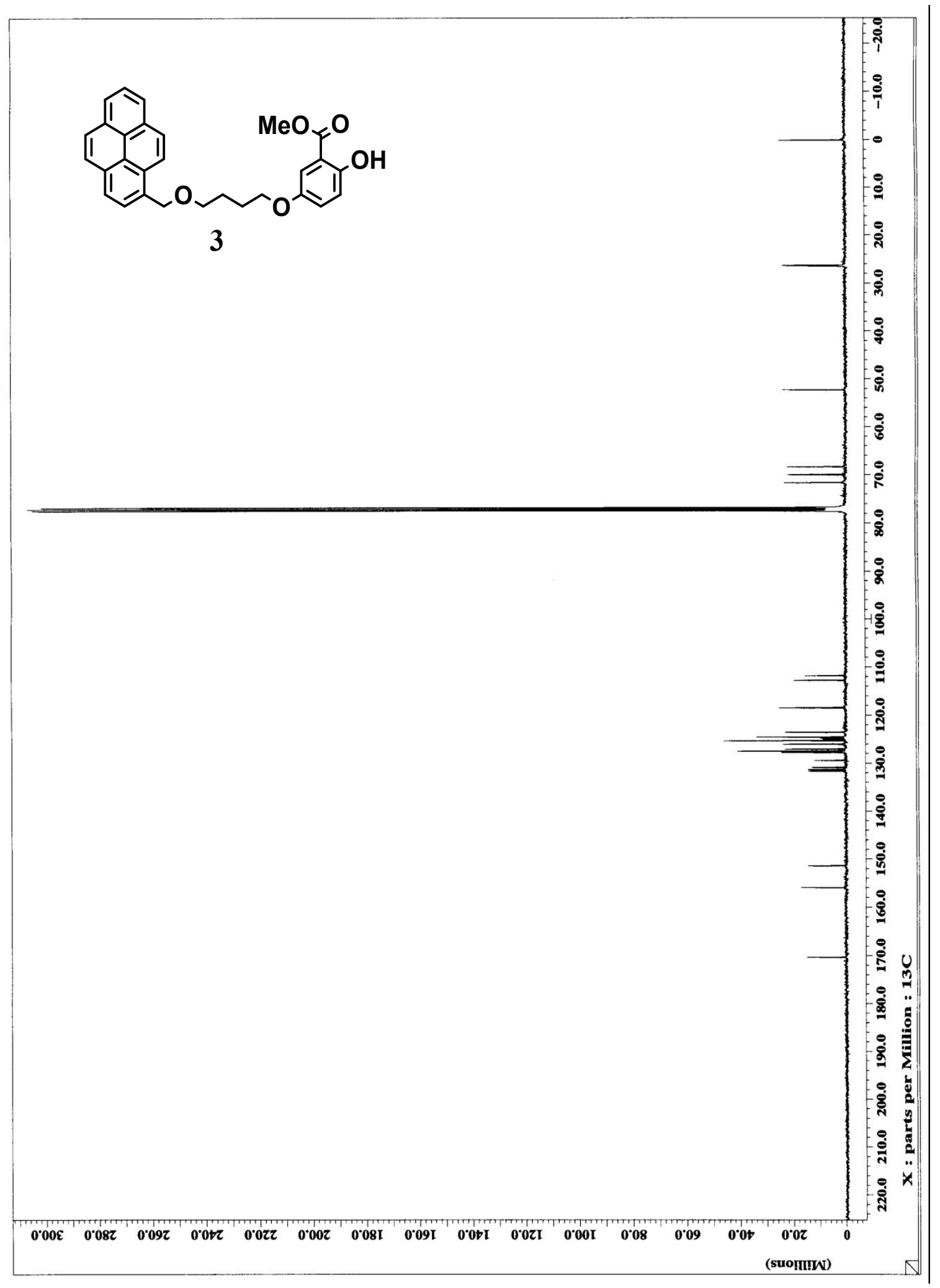




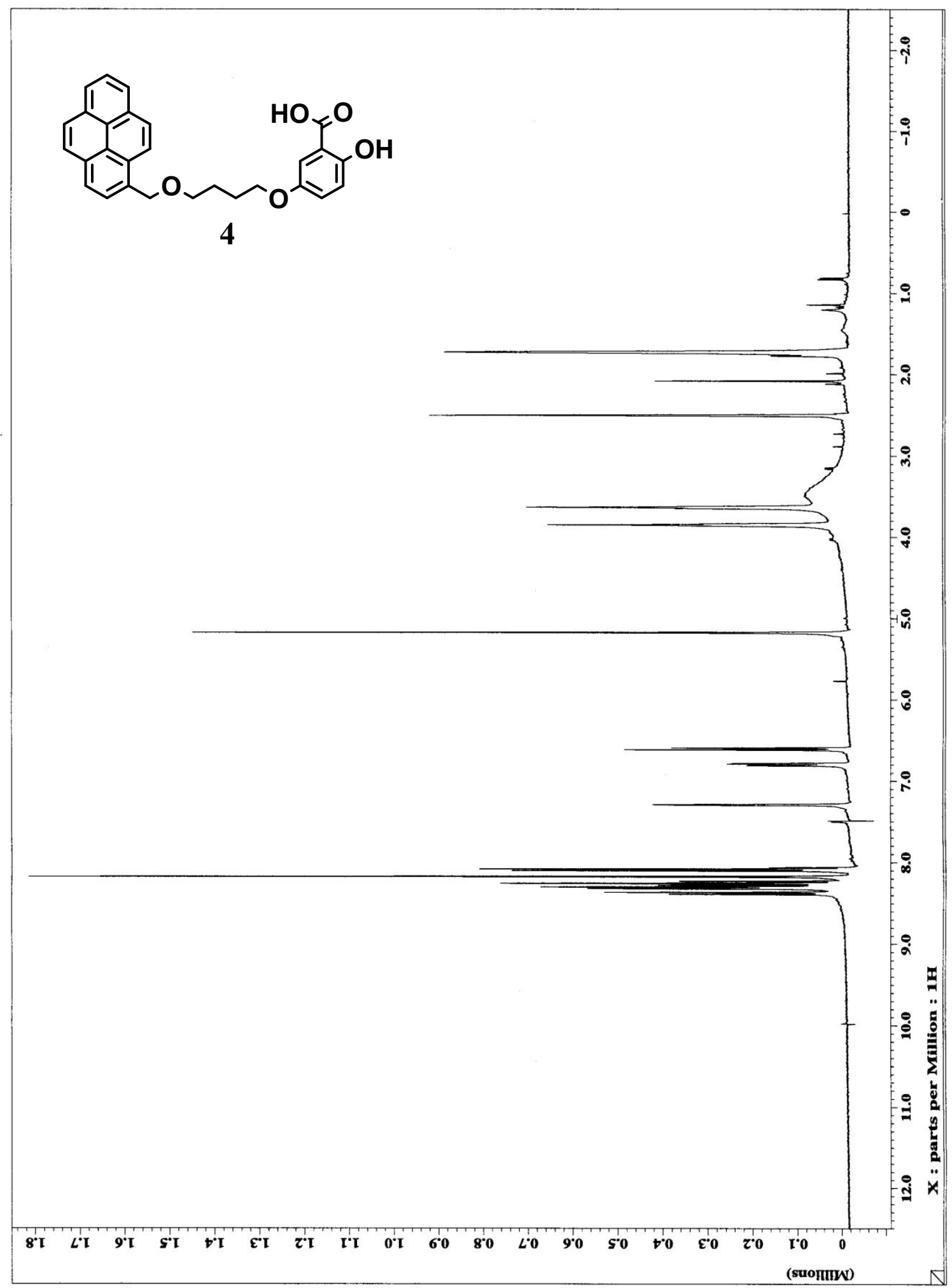




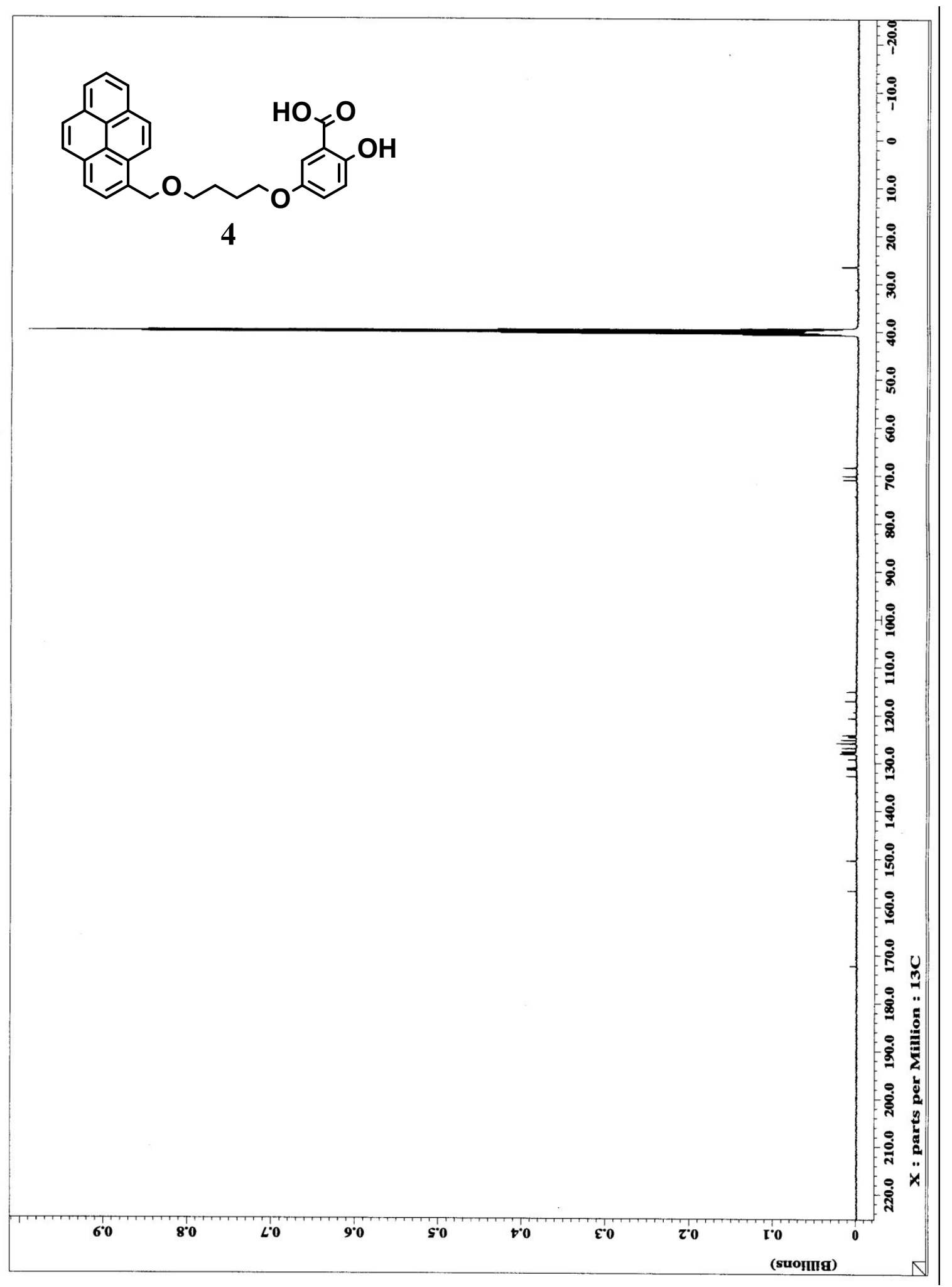

